\title{
Plasma Phosphatidylcholine Alterations in Cystic Fibrosis Patients: Impaired Metabolism and Correlation with Lung Function and Inflammation
}

\author{
Judith Grothe $\quad$ Joachim Riethmüllerb,c Sandra M. Tschürtz ${ }^{\mathrm{a}} \quad$ Marco Raith $^{\mathrm{a}}$ \\ Chris J. Pynn a,e Dieter Stolld,e Wolfgang Bernhard ${ }^{a}$
}

Departments of ${ }^{\mathrm{a} N e o n a t o l o g y},{ }^{\mathrm{b}} \mathrm{General}$ Pediatrics, Hematology\&Oncology and ${ }^{\mathrm{C} C e n t e r}$ for Pediatric Clinical Studies, Faculty of Medicine, Eberhard-Karls-University, Tübingen, Germany; ${ }^{\mathrm{d} D e p t}$. of

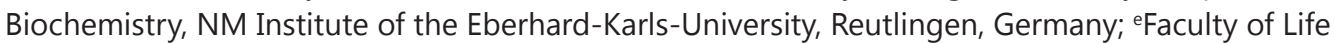
Sciences, Albstadt-Sigmaringen University, Sigmaringen, Germany

\section{Key Words}

Cystic Fibrosis - Choline deficiency • Phospholipid metabolism • Stable isotope labeling in patients

\begin{abstract}
Background: Liver impairment, ranging from steatosis to cirrhosis, is frequent in cystic fibrosis (CF) patients and is becoming increasingly significant due to their improved life expectancy. One aspect of hepatic alterations is caused by increased fecal loss of the essential nutrient choline, following enterohepatic bile phosphatidylcholine (PC) cycle impairment. Hepatic PC synthesis, both de novo and via phosphatidylethanolamine-N-methyl-transferase (PEMT), is essential for very low-density lipoprotein (VLDL) secretion. VLDL-PC in particular contributes to the organism's supply with polyunsaturated fatty acids (LC-PUFA), namely arachidonic (C20:4) and docosahexaenoic acid (C22:6). Consequently, choline deprivation and altered hepatic PC metabolism may affect plasma PC homeostasis and extrahepatic organ function. Objectives: To investigate relationships between altered plasma choline and PC homeostasis and markers of lung function and inflammation in CF. To assess alterations in hepatic choline and PC metabolism of CF patients. Design: Quantification of plasma/serum choline and PC species in adult CF patients compared to controls. Correlation of PC with forced expiratory vital capacity $\left(\mathrm{FEV}_{1}\right)$ and interleukin 6 (IL-6) concentrations. Analysis of choline and PC metabolism in CF compared to controls, using deuterated choline ([ $\mathrm{D}_{9}$-methyl]-choline) labeling in vivo. Results: Mean choline and PC concentrations in CF patients were lower than in controls. Choline and PC concentrations as well as fractions of C22:6-PC and C20:4-PC correlated directly with $\mathrm{FEV}_{1^{\prime}}$ but inversely with IL-6. Plasma concentrations of deuterated PC were decreased for both pathways, whereas only in PC synthesized via PEMT precursor enrichment was decreased.
\end{abstract}

J. Grothe and J. Riethmüller equally contributed to this work.

\begin{tabular}{ll}
\hline Wolfgang Bernhard, & Department of Neonatology, Children's Hospital, \\
Dr. med., Dr. rer. physiol., Prof. & Eberhard-Karls-University, Calwer Straße 7, D-72076 Tübingen, FRG (Germany) \\
& Tel. +49 70712986377, E-Mail wolfgang.bernhard@med.uni-tuebingen.de
\end{tabular}


Conclusion: In CF patients, hepatic and plasma homeostasis of choline and PC correlate with lung function and inflammation. Impaired hepatic PC metabolism, exemplarily shown in three CF patients, provides an explanation for such correlations. Larger studies are required to understand the link between hepatic PC metabolism and overall clinical performance of CF patients, and the perspective of choline substitution of these patients.

Copyright $@ 2015$ S. Karger AG, Basel

\section{Introduction}

Cystic Fibrosis (CF) is an autosomal recessive disease caused by mutations in the Cystic Fibrosis Transmembrane Conductance Regulator (CFTR), a cyclic adenosine monophosphate activated chloride channel [1]. Improved treatment of exocrine pancreas insufficiency by enzyme substitution and inhibition of pulmonary decay by antibiotic, enzymatic and physical therapies have significantly improved life expectancy within the last 30 years, resulting in median survival between 38.3 and 48.5 years [2, 3]. As a result of such improvements, liver disease has started to become a clinical issue in CF. It is assumed that hepatobiliary abnormalities occur in approximately $13-27 \%$ of pediatric CF patients and $30-72 \%$ of adults with $\mathrm{CF}$, although being frequently subclinical. Alterations range from hepatic steatosis and gallstones to cholestasis, cholangitis, fibrosis and focal biliary cirrhosis [4-7]. Minor affections as hepatosteatosis or gallstones should be discriminated from CF related liver disease (CFRLD), which frequently leads to fibrosis and cirrhosis. The former are primarily related to malnutrition and nutrient losses, like choline, linoleic acid and other long chain polyunsaturated acids (LC-PUFA), where the enterohepatic choline metabolism is a potential key factor $[4,8,9]$. Animal experiments show that impaired choline, phosphatidylcholine (PC) and essential fatty acid homeostasis is linked to liver failure $[4,10,11]$. However, these nutrients are relevant beyond liver function (see below).

A link from the genetic defect to liver impairment in CF is the loss of CFTR function in cholangiocytes [12]. Here, impaired chloride secretion affect bicarbonate, electrolyte, fluid and $\mathrm{pH}$ homeostasis. In the Phe508del mouse model of CF, cholangiocyte impairment is associated with an increased secretion and fecal losses of bile salts. Additionally, biliary phospholipid secretion and fecal losses are increased [7]. In human CF patients, fecal losses of choline metabolites derived from biliary phosphatidylcholine (PC), are increased despite pancreatic enzyme replacement. Fecal losses of undigested PC are 9-fold increased, suggesting that impaired pancreatic phospholipase $A_{2}\left(p P L a s e A_{2}\right)$ function is causative here, and choline deficiency may be central to metabolic alterations in CF [13-15].

The clinical relevance of the enterohepatic $\mathrm{PC} /$ choline cycle for CF bases on quantitative as well as qualitative aspects: a $1500 \mathrm{~g}$ adult liver comprises about $30 \mathrm{mmol}(22.5 \mathrm{~g})$ PC, of which $5-10 \mathrm{~g} / \mathrm{d}$ are secreted via bile $[16,17]$. This equals a daily turnover of $22-44 \%$ of total liver PC, being equivalent to $0.7-1.4 \mathrm{~g}$ choline, a 1.25-2.5 fold of the adequate daily intake (AI) of an adult male $(0.55 \mathrm{~g} / \mathrm{d})[18]$. Characteristically, maintenance of biliary PC secretion has biological priority over liver integrity and choline/PC distribution to peripheral organs via lipoproteins [11]. Sufficient hepatic PC synthesis using choline, or via methylation of phosphatidylethanolamine (PE) by PE-N-methyltransferase (PEMT), are essential to the assembly and secretion of very low density lipoproteins (VLDL), thereby integrating hepatic lipid and precursor metabolism with peripheral organ supply, since VLDL comprise about $20 \%$ PC [19]. Moreover, choline is a source to generate betaine, a methyl-group donator to regenerate methionine from homocysteine, the former being essential for the PEMT pathway $[20,21]$ : the activated form of methionine, S-adenosyl-methionine (SAM), is co-substrate of PEMT for PC formation from polyunsaturated PE. Here, deficiency in methyl donators is consistent with decreased methionine and increased homocysteine concentrations in CF children [22, 23]. Hence, fecal choline losses in CF may affect choline, one-carbon unit, PC and LC-PUFA homeostasis of the liver. Due to the central role of this organ, these considerations suggest an impairment of peripheral supply and functional consequences, 


\section{Cellular Physiology Cell Physiol Biochem 2015;35:1437-1453 \\ \begin{tabular}{l|l|l} 
DOI: 10.1159/000373964 & $\begin{array}{l}\text { O 2015 S. Karger AG, Basel } \\
\text { www.karger.com/cpb }\end{array}$ \\
and Biochemistry & Published online: March 12, 2015 & Gris.
\end{tabular} \\ Grothe et al:: Clinical Impact of Phospholipid Alterations in CF}

which are primarily caused by a disturbed enterohepatic cycle of choline rather than the severity of CFRLD.

So far, a link between hepatic choline and PC homeostasis and extrahepatic, clinically relevant parameters is missing. Predicted forced expiratory volume in 1 second $\left(\mathrm{FEV}_{1}\right)$ has proved to be a generally accepted indicator of lung function, correlating with nutrition, while interleukin 6 (IL-6) is an established inflammation marker [2,3]. We therefore set out to quantify plasma concentrations of choline, betaine, total PC and PC composition in adult $\mathrm{CF}$ patients compared to healthy volunteers. We then correlated in CF patients choline and its metabolites with FEV ${ }_{1}$ and IL- 6 concentrations. Differences in choline and PC metabolism in $\mathrm{CF}$ compared to healthy adults were addressed using deuterated choline ([D $\mathrm{D}_{9}$-methyl]choline) in vivo. Our data suggest a clinically relevant link between phospholipid metabolism of the liver, lung function and inflammation in CF patients.

\section{Materials and Methods}

The study was approved by the local Ethics committee (University of Tübingen) and written and informed consent obtained by participants

\section{Chemicals}

Chloroform was of HPLC grade and from Baker (Deventer, The Netherlands). Methanol, water and ammonium hydroxide were of analytical grade and from Fluka Analytical/Sigma-Aldrich (Munich, Germany). Phospholipid standards were from Avanti Polar Lipids (Alabaster, AL, USA) or from Sigma-Aldrich (Munich, Germany), and purity checked by tandem mass Spectrometry (see below). Deuterated choline ([ $D_{9}$-methyl] choline) chloride was purchased from Dr. Ehrenstorfer GmbH (Augsburg, Germany). All other chemicals were of analytical grade and from various commercial sources.

\section{Study population}

Eleven CF patients (5 females; all homozygous for Phe508del and 10 volunteers (5male/5female) participated in the study. All CF patients had ambulatory control visits at least every 3 months, and no CF patient had a history of allergic bronchopulmonary aspergillosis requiring systemic glucocorticoid treatment. Patients received standard treatment with pancreatic enzyme replacement, inhaled glucocorticoids \& beta-mimetics, and antibiotic treatment in case of Pseudomonas aeruginosa colonization $(\mathrm{N}=10) .3$ male $\mathrm{CF}$ patients and 4 (1 female) healthy volunteers approved the $\left[\mathrm{D}_{9}\right.$-methyl]choline labeling experiments. Of these latter CF patients, one showed no pathological ultrasound or serologic signs of liver disease, whereas one was diagnosed with steatosis, but no cirrhosis. The third patient suffered from liver cirrhosis as evident on ultrasound.

\section{Lung function and IL-6 determination}

Lung function of the CF patients was assessed during their visits to the local CF clinic from 2007-2009 (7-9 per patient) using bodyplethysmography/spirometry (Jaeger, Höchberg, Germany). Blood samples were also taken. IL-6 concentration was determined in serum by the Tuebingen university hospital clinical laboratory. A plasma aliquot was prepared from each sample, which was processed as described below.

\section{Labeling of patients with [ $D_{9}$-methyl]choline}

A sterile aqueous solution of [methyl- $\mathrm{D}_{9}$ ] choline chloride $(25 \mathrm{mg} / \mathrm{ml})$ was prepared by the Tuebingen university hospital's pharmacy department, aliquoted in 5 and $10 \mathrm{ml}$ glass vials, and stored at $-80^{\circ} \mathrm{C}$ until use. Representative samples were analyzed to ensure that they were sterile and to confirm the absence of pyrogens. All procedures were performed under standardized conditions, according to good pharmaceutical practice, by the local pharmaceutical unit at the University of Tübingen, as described before. For infusion, aliquots of stock solutions equivalent to $3.6 \mathrm{mg} / \mathrm{kg}$ body weight were drawn into a $50 \mathrm{ml}$ syringe and sterile isotonic saline added to make $50 \mathrm{ml}$ total volume. This solution was continuously infused into a forearm vein of overnight fasted participants over 3 hours $(0.278 \mathrm{ml} / \mathrm{min})$ using an infusion pump. Patients were mobile and were allowed to drink water during the infusion. Eating was allowed following completion of 


\section{Cellular Physiology Cell Physiol Biochem 2015;35:1437-1453 \begin{tabular}{l|l|l} 
DOI: 10.1159/000373964 & (C) 2015 S. Karger AG, Basel
\end{tabular} and BiOChemistry Published online: March 12, $2015 \quad$ www.karger.com/cpb \\ Grothe et al.: Clinical Impact of Phospholipid Alterations in CF}

the infusion. Blood samples (2.7ml EDTA-tubes) were collected from a vein of the other forearm directly before (-5min) and at 1, 3, 6, 9, 24, 33, 48 and 72 hours after the start of infusion. Blood samples were immediately centrifuged at $1000 \mathrm{xg}, 4^{\circ} \mathrm{C}$ for $15 \mathrm{~min}$, plasma aspirated, aliquoted and stored at $-80^{\circ} \mathrm{C}$ until analysis.

Analysis of plasma lipids and water soluble PC precursors

Blood samples were harvested, and kept at $4^{\circ} \mathrm{C}$ until routine serum (or EDTA plasma for labeling experiments) isolation. Samples were centrifuged at $1000 \mathrm{xg}$ for $10 \mathrm{~min}$, cell-free supernatants aspirated, and stored in $50-100 \mu \mathrm{L}$ aliquots at $-80^{\circ} \mathrm{C}$. Total PC and PC molecular species composition were determined by HPLC (see below).

To $500 \mu \mathrm{L}$ plasma was added $10 \mu \mathrm{L}$ butylhydroxytoluol $(20 \mathrm{mg} / \mathrm{ml}$ ethanol) as an antioxidant along with $100 \mu \mathrm{L}\left[\mathrm{D}_{4}\right]$ choline chloride $(30 \mu \mathrm{mol} / \mathrm{L}$ in double distilled water $)$ as an internal standard. Samples were extracted according to Bligh and Dyer [25], and the respective hydrophilic upper phase containing the water soluble precursors or metabolitesand organic lower phase containing the lipids were then subjected for further analyses. Total phospholipids in the organic phase were determined according to Bartlett after digestion of the organic compounds as previously described [26]. Comparison of EDTA plasma and serum for total phospholipid, PC and PC molecular species analysis with HPLC (see below) showed no differences in these parameters (data not shown).

\section{High performance liquid chromatography of plasma PC}

Routine analysis of PC molecular species and sphingomyelin (SPH) was performed from lipid extracts using high performance liquid chromatography (HPLC) as described before [26]. Briefly, PC/SPH was prepared from $500 \mathrm{nmol}$ plasma phospholipid aliquots using $100 \mathrm{mg}$ Strata $\mathrm{NH}_{2}$ disposable cartridges (Phenomenex Inc., USA) and dimyristoyl-PC as an internal standard. Isocratic separation of individual molecular species was then performed with a 4.6 x 250mm Sphere Image ODS II column (Schambeck, Bad Godesberg, Germany) at $50^{\circ} \mathrm{C}$, methanol:water choline chloride (925:75:7.6, v/v/w) as the mobile phase and post-column fluorescence derivative formation of $\mathrm{PC}$ in the presence of 1,6-diphenyl-1,3,5-hexatriene [25].

ESI-MS/MS analysis of [methyl- $D_{9}$ ] choline and [methyl- $\left.D_{9}\right]$ betaine

Endogenous (unlabeled) choline and its derivative betaine as well as [methyl- $\mathrm{D}_{9}$ ]choline, [methyl- $\mathrm{D}_{9}$ ] betaine and the internal standard $\left[1,1,2,2-\mathrm{D}_{4}\right]$ choline were analyzed with electrospray ionization tandem mass spectrometry (ESI-MS/MS) [24], using an Atlantis ${ }^{\circledR}$ HILIC Silica $3 \mu \mathrm{m}$ column $\left(2.1 \times 30 \mathrm{~mm} ; 50^{\circ} \mathrm{C}\right)$ using a HP1100 LC system (Agilent Technologies, Heilbronn, Germany) on a Waters Micromass Quattro Micro API triple quadrupole mass spectrometer (Waters, Dreieich, Germany), supplied with an electrospray ionization interface. Components were analyzed by specific reaction monitoring (SRM) in the positive ionization mode, using mass by charge (m/z) transitions of 104 60 (choline), 108 $\rightarrow 61\left(\mathrm{D}_{4}\right.$-choline), $113 \rightarrow 69\left(\left[\mathrm{D}_{9}\right.\right.$-methyl]-choline), $118 \rightarrow 59$ (betaine), $127 \rightarrow 68\left(\left[\mathrm{D}_{9}\right.\right.$ methyl]-betaine), $184 \rightarrow 86$ (phosphocholine) and $193 \rightarrow 95\left(\mathrm{D}_{9}\right.$-phosphocholine). Samples were quantified by comparing the areas of each SRM with external calibration curves for the respective metabolite using $\mathrm{D}_{4}$-Choline as internal standard. Comparison of EDTA plasma with serum of control samples ( $\mathrm{N}=7$ ) showed no difference for choline (means \pm SE) $(13.07 \pm 1.05$ and $12.68 \pm 0.69 \mu \mathrm{mol} / \mathrm{L}$, respectively; $p=0.4505)$ whereas for betaine serum values were $27.8 \%$ increased in serum by paired t-test comparison $(32.82 \pm 5.41$ and $41.93 \pm 6.5 \mu \mathrm{mol} / \mathrm{L}$, respectively; $p<0.0004$ ). Consequently, serum betaine was corrected by multiplying values by 0.7827 .

\section{ESI-MS/MS analysis of endogenous and stable isotope labeled PC and of endogenous PE}

Analysis of phospholipids containing a choline headgroup (PC, lyso-PC, SPH) and of PE was performed as described before [21, 27], using a Thermo TSQ Quantum Discovery MAX triple quadrupole mass spectrometer (Thermo, Dreieich, Germany) equipped with a heated electrospray ionization (H-ESI) interface. In brief, $25 \mu \mathrm{L}$ sample $(6 \mu \mathrm{mol} / \mathrm{L}$ phospholipid in butanol:methanol:water $(75: 23: 2, \mathrm{v} / \mathrm{v}))$ containing dieicosanoyl-PC and dimyristoyl-PC as internal standards were introduced via loop injection using a Finnigan Surveyor Autosampler Plus and MS Pump Plus (Thermo, Dreieich, Germany), and a mobile phase comprising butanol:methanol:water:25\% $\mathrm{NH}_{4} \mathrm{OH}(75: 23: 1.7: 0.3 ; \mathrm{v} / \mathrm{v})$. PC species were quantified 


\section{Cellular Physiology Cell Physiol Biochem 2015;35:1437-1453 \begin{tabular}{l|l|l} 
DOI: 10.1159/000373964 & (C) 2015 S. Karger AG, Basel
\end{tabular} and BIOChemistry Published online: March 12, $2015 \quad$ www.karger.com/cpb

from precursor ions of the respective diagnostic fragment ions. These were phosphocholine for endogenous PC, lyso-PC and SPH (mass / charge $(\mathrm{m} / \mathrm{z})=184)$, $\mathrm{D}_{9}$-phosphocholine $(\mathrm{m} / \mathrm{z}=193)$ for PC synthesized de novo by direct [methyl- $\mathrm{D}_{9}$ ]choline incorporation, and $\mathrm{D}_{3}$-phosphocholine $(\mathrm{m} / \mathrm{z}=187)$ and $\mathrm{D}_{6}$-phosphocholine $(\mathrm{m} /$ $\mathrm{Z}=190$ ) for PC synthesized by sequential PE N-methylation to yield PC. Here, sequential transfer of one or two deuterated methyl groups $\left(\mathrm{CD}_{3}-\right)$ from $\mathrm{D}_{3}$-S-adenosylmethionine originating from $\left[\mathrm{D}_{9}\right.$-methyl]-choline catabolism leads to mass shifts of PC species of $M+3$ and $M+6$. PE species were analyzed from the neutral loss fragment phosphoethanolamine $(\mathrm{m} / \mathrm{z}=+141)$ of the individual masses.

\section{Calculation of MS/MS data}

Total ion counts of PC and PE species analysis were collected in Excel spread sheets using XCalibur® Version 2 Software (Thermo). Data were then processed using an Excel-based in-house macro for correction of ${ }^{13} \mathrm{C}$ isotope effects of individual molecular species and reduced response with increasing $\mathrm{m} / \mathrm{z}$ values. According to the low enrichment of PC with $D_{3}$-methyl groups via PEMT, $(M+3 ; m / z=187)$, overspill from the diagnostic fragment of the naturally occurring $M+3$ analogue $(\mathrm{m} / \mathrm{z}=187)$ of endogenous $\mathrm{PC}$ was included in the calculation of $\mathrm{D}_{3}$-labelled PC. From these data the molecular composition of endogenous PC species and those newly synthesized via de novo synthesis ( $\mathrm{D}_{9}$-labeled $\mathrm{PC}$ ) as well as via PE methylation pathway $\left(\mathrm{D}_{3}-\mathrm{D}_{6}\right.$-labeled $\left.\mathrm{PC}\right)$ were calculated. Concentrations of individual PC species were calculated from the internal standard. From these data, we determined the $\mathrm{D}_{9}-\mathrm{D}_{3}-$ \& $\mathrm{D}_{6}$ - enrichments and their absolute plasma concentrations at time points ( 3 to $72 \mathrm{~h}$ after start of infusion) for total PC, individual PC species and PC subgroups. The $\mathrm{D}_{3}$ - and $\mathrm{D}_{6}$-enrichment of $\mathrm{PC}$ was used to calculate the $\mathrm{D}_{3}$-enrichment of $\mathrm{SAM}$, according to the formula ( $\Sigma \mathrm{D} 6-\mathrm{PC} /(\Sigma \mathrm{D} 3-\mathrm{PC}+\Sigma \mathrm{D} 6-\mathrm{PC}))$ as described before [21]. PC and PE subgroups were generated from individual PC molecular species by summing up species containing a monounsaturated (oleic acid, C18:1), diunsaturated (linoleic acid, C18:2), arachidonic (C20:4) or docosahexaenoic (C22:6) acid [27].

\section{Statistical analysis}

Data are indicated as means and standard deviation. Statistical analysis was performed using Instat, version 3.10 (GraphPad, La Jolla, CA, USA). Spearman Rank test was used for regression analysis after test for linearity, and the Mann-Whitney-test for group comparisons. P values below 5\% were regarded as statistically significant.

\section{Results}

\section{Endogenous choline, betaine and phosphatidylcholine concentrations}

In CF patients plasma choline concentration was $8.51 \pm 0.61 \mu \mathrm{mol} / \mathrm{L}($ mean $\pm \mathrm{SE})$, whereas in control subjects it was $10.85 \pm 0.96 \mu \mathrm{mol} / \mathrm{L}(p<0.05)$. In those individuals participating in the $\left[\mathrm{D}_{9}\right.$-methyl]choline labeling experiment endogenous choline concentration did not change over the whole sampling period $(\mathrm{N}=10$ samples over $72 \mathrm{~h})$, and was $6.40 \pm 0.32$ and $7.82 \pm 0.27 \mu \mathrm{mol} / \mathrm{L}$ in CF and control subjects, respectively $(p<0.01)$. Endogenous betaine was $20.88 \pm 2.09 \mu \mathrm{mol} / \mathrm{L}$ for the whole CF collective, compared to $30.28 \pm 4.15 \mu \mathrm{mol} / \mathrm{L}$ in controls $(p<0.05)$.

Total plasma/serum PC concentration was $2.18 \pm 0.16$ and $1.36 \pm 0.09 \mathrm{mmol} / \mathrm{L}$ in controls andCFpatients, respectively $(p<0.05)$, whereasSPHwas $0.111 \pm 0.006$ and $0.084 \pm 0.007 \mathrm{mmol} / \mathrm{L}$, respectively $(\mathrm{p}<0.01)$. Concentrations of palmitoyl-oleoyl-PC (PC16:0/18:1) were identical in $\mathrm{CF}$ and controls, whereas palmitoyl-linoleoyl-PC (PC16:0/18:2), stearoyl- linoleoylPC (PC18:0/18:2) and oleoyl-linoleoyl-PC (PC18:1/18:2) were decreased (Fig. 1). There were no significant differences in the concentrations of LC-PUFA containing PC, i. e. those molecular species containing arachidonic (C20:4) or docosahexaenoic (C22:6) acid.

According to the assumed impact of LC-PUFA homeostasis for CF patients' clinical situation [28, 29], we analyzed the variability of biochemical values, to correlate them with clinical parameters. The minimum to maximum range was 4.32 to $8.85 \mathrm{mmol} / \mathrm{L}$ for choline (2.05fold) and 0.801 to $1.836 \mathrm{mmol} / \mathrm{L}$ for total PC $(2.29 \mathrm{fold})$. It was higher for C20:4-PC (99.84 to $422.55 \mu \mathrm{mol} / \mathrm{L})$ and C22:6-PC (38.16 to $113.19 \mu \mathrm{mol} / \mathrm{L})(4.23 \mathrm{fold}$ and 2.97fold, respectively) than for C18:1-PC (159.01 to $342.26 \mu \mathrm{mol} / \mathrm{L})$ and C18:2-PC (303.41 
Fig. 1. Concentration of major PC molecular species in plasma of CF patients compared to healthy controls. Data are means \pm SD of 9-10 averaged measurements of $11 \mathrm{CF}$ individuals (black bars) compoared to controls $(\mathrm{N}=10$; white bars). Abbreviations: PC16:0/18:1, palmitoyl-oleoyl-PC; PC16:0/18:2, palmitoyl-linoleoyl-PC; PC18:0/18:2, stearoyl-linoleoyl-PC; PC18:1/18:2, oleoyl-linoleoyl-PC; PC16:0/20:4, palmitoyl-arachidonoyl-PC; PC18:0/20:4, stearoyl-arachidonoyl-PC; PC16:0/22:6, palmitoyl-docosahexaenoyl-PC; PC18:0/22:6, stearoyl-docosahexaenoyl-PC; C18:2PC, PC species containing linoleic acid;

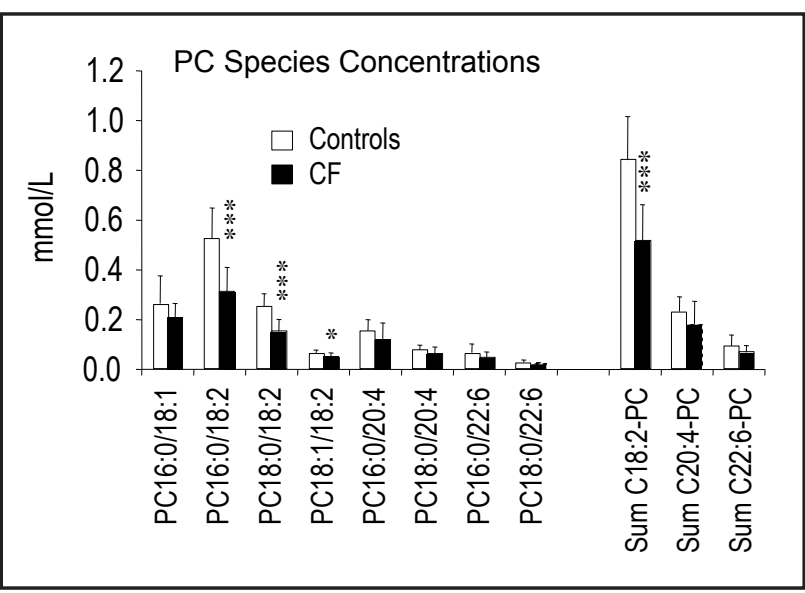
C20:4-PC, PC species containing arachidonic acid; C22:6-PC, PC species containing docosahexaenoic acid; $*, \mathrm{p}<0.05 ; * *, \mathrm{p}<0.01$.

Fig. 2. Correlation of choline and phosphatidylcholine (PC) concentrations in serum versus $\mathrm{FEV}_{1}$ and IL-6 concentration. $\mathrm{FEV}_{1}$ (A,B) and IL-6 (C,D) as clinical markers of lung function and systemic inflammation in CF patients, respectively, were correlated with serum concentrations of choline $(A, C)$ and phosphatidylcholine $(B, D)$, respectively. Values are individual data pairs $(\mathrm{N}=65)$ from 8-9 sequential visits of $\mathrm{CF}$ patients. Overall regression is indicated by a solid line, whereas dashed lines indicate intra-individual correlation. Abbreviations: p, significance level; r, correlation coefficient.

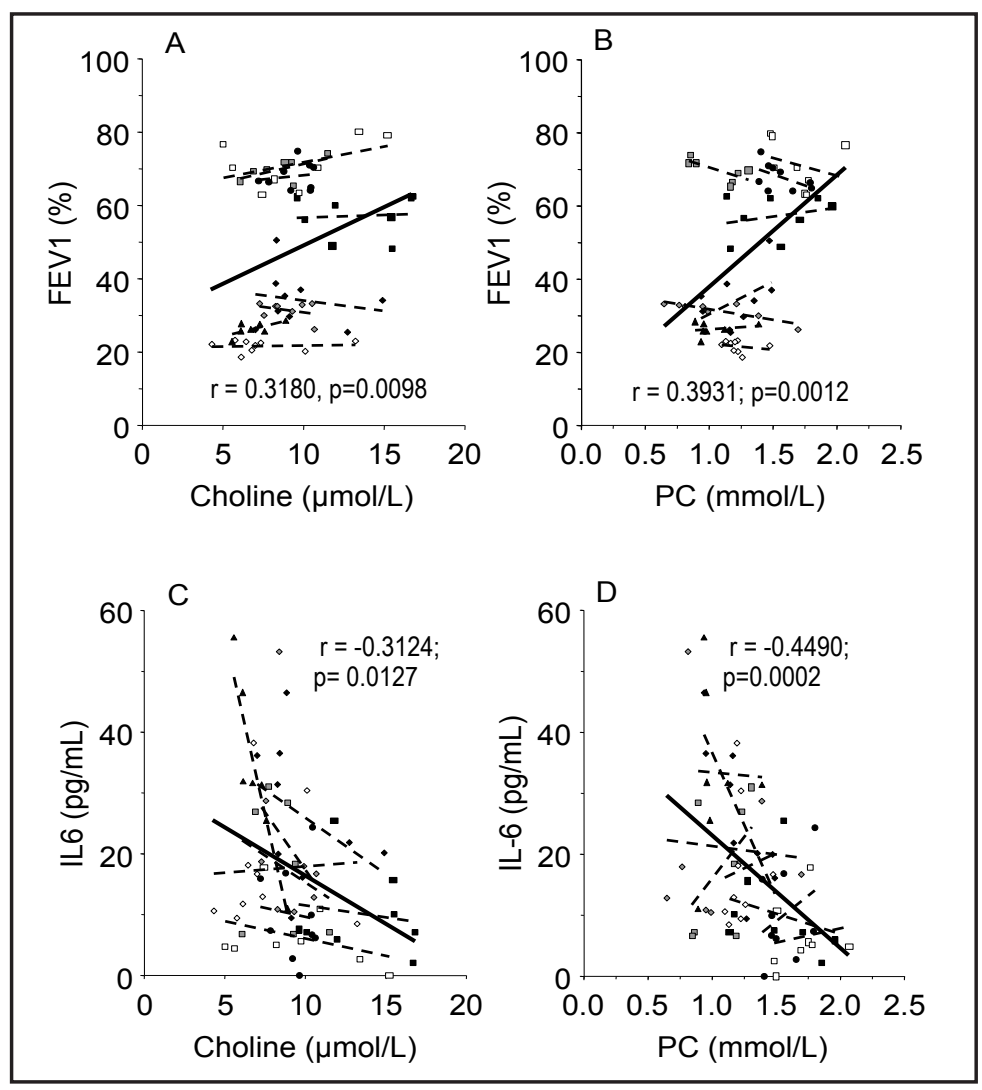

to $735.8 \mu \mathrm{mol} / \mathrm{L}$ ) (2.15 and 2.43 fold, respectively). This similarly applied to molecular composition, where C20:4-PC ranged from 10.29 to 23.18\%, and C22:6-PC from 3.19 to $8.10 \%$ (2.25 and 2.54fold, respectively). By contrast, the min to max range of C18:1-PC (14.44 to $22.04 \%$ ) and C18:2-PC (34.7 to $50.87 \%$ ) was only 1.53 and 1.46 fold, respectively.

Correlation of plasma choline and PC concentration with lung function

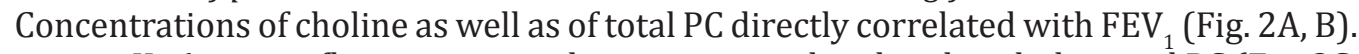
By contrast, IL-6 as an inflammation marker was inversely related to choline and PC (Fig. 2C, D). We then set out to investigate whether there was any relationship between the fractions 
Fig. 3. Correlation of polyunsaturated serum phosphatidylcholines relative to $\mathrm{FEV}_{1}$ and IL-6 concentration. FEV as a clinical marker of lung function (A,B) and serum IL-6 concentration as a marker of systemic inflammation (C,D) in $\mathrm{CF}$ patients were correlated with the molar fraction of phosphatidylcholine (PC) species containing an arachidonic acid (C20:4-PC) (A,C) or a docosahexaenoic acid residue (C22:6-PC) (B,D). Values are individual data pairs $(\mathrm{N}=65)$ from 8-9 sequential visits of CF patients. Overall regression is indicated by a solid line, whereas dashed lines indicate intra-individual correlation. Abbreviations: p, significance level; r, correlation coefficient.
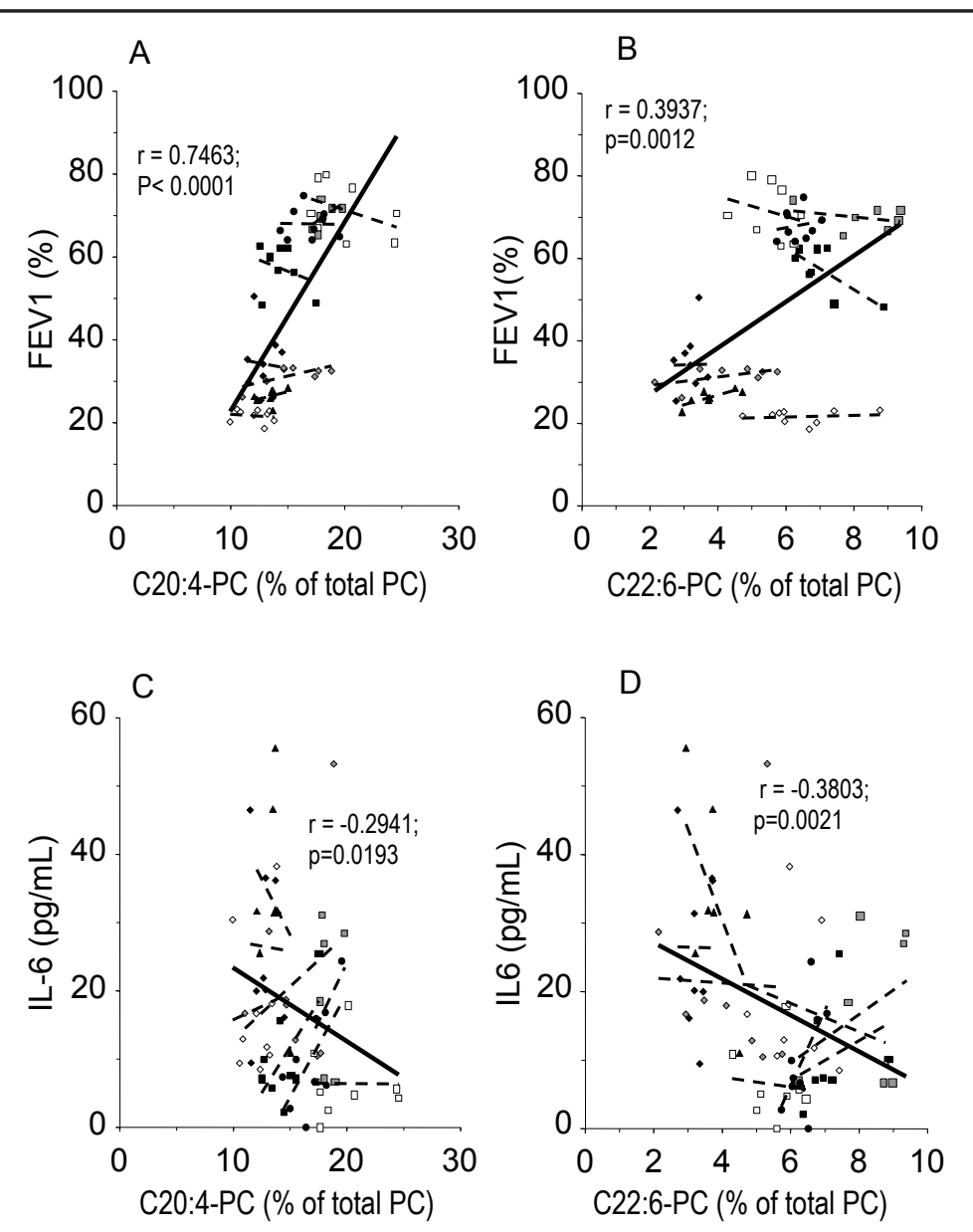

of PC sub-groups and the clinical parameters measured. Fractions of C20:4-PC and C22:6-PC were increased in patients with better lung function $\left(\mathrm{FEV}_{1}\right)$ (Fig. 3A, B). By contrast, they were inversely related to IL-6 concentrations in serum (Fig. 3C, D). However, these overall

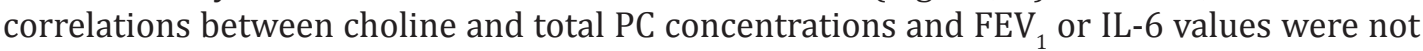
consistently found intra-individually. Here correlation coefficients showed a wide range for choline and total PC concentrations, particularly relative to $\mathrm{FEV}_{1}$ (Fig. 2A, B). This similarly

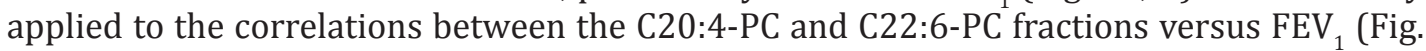
$3 \mathrm{~A}, \mathrm{~B}$ ). In particular, the correlation of $\mathrm{FEV}_{1}$ versus C22:6-PC (Fig. 3B), but also $\mathrm{FEV}_{1}$ versus choline, total PC and C20:4-PC (Fig. 2A, B, Fig. 3A) suggested the existence of two patient subgroups. By contrast, there was no significant correlation between plasma betaine and FEV $_{1}$ or IL-6 (data not shown).

\section{Concentrations and deuterium-enrichment of water soluble PC precursors}

We then investigated, whether in CF patients compared to control subjects choline and PC metabolism is characteristically different. Detailed patient and control data are given in Table 1. While body size and weight in these CF patients were below those of the controls, their body mass indexes were almost identical. Clinical data showed no major impairments in terms of blood protein and cells, coagulation, biliary function, hepatocyte integrity (AST, ALT, $\mathrm{LDH}, \mathrm{AP}$ and $\gamma \mathrm{GT}$ ), and renal function. $\mathrm{FEV}_{1}$ was lower in CF patients compared to controls. As expected, blood leucocytes were higher in CF patients, whereas serum cholesterol was lower.

There was no difference in the plasma kinetics of $\left[D_{9}\right.$-methyl $]$-choline between $\mathrm{CF}$ patients and controls (Fig. 4A). [ $\mathrm{D}_{9}$-methyl]-choline rapidly increased 
Table 1. Clinical parameters of patients receiving $\left[\left[\mathrm{D}_{9}\right.\right.$-methyl]choline $]$. Means \pm $\mathrm{SD}$, and (min-max) values are indicated. Abbreviations: PTT, partial thromboplastin time; ALT, alanine aminotransferase; AST, aspartate aminotransferase; LDH, lactate dehydrogenase; AP, alkaline phosphatase; GGT, gamma glutamyl transpeptidase; *: $\mathrm{p}<0.05$

\begin{tabular}{|c|c|c|}
\hline & Healthy Controls $(\mathrm{N}=4)$ & CF patients ( $\mathrm{N}=3$ ) \\
\hline Age (years) & $28.7 \pm 9.4(22.8-42.6)$ & $23.5 \pm 4.7(19.8-28.8)$ \\
\hline Size $(\mathrm{m})$ & $1.80 \pm 0.03(1.76-1.83)$ & $1.76 \pm 0.06(1.71-1.83)^{*}$ \\
\hline Body weight (kg) & $72.3 \pm 9.4(61.0-80.0)$ & $63.4 \pm 5.6(57.0-66.8)^{*}$ \\
\hline Body mass index & $22.3 \pm 2.1(19.7-24.2)$ & $20.6 \pm 1.5(19.5-22.2)$ \\
\hline FEV1 (\% of FVC) & $90.1 \pm 8.2(80.3-99.0)$ & $75.6 \pm 4.6(70.3-78.7) *$ \\
\hline Plasma protein $\left(\mathrm{g} \mathrm{x} \mathrm{dL}^{-1}\right)$ & $7.8 \pm 0.1(7.5-8.0)$ & $7.9 \pm 0.6(6.8-8.6)$ \\
\hline Erythrocytes $\left(10^{6} \times \mathrm{xL}^{-1}\right)$ & $4.65 \pm 0.12(4.34-4.85)$ & $5.05 \pm 0.32(4.41-5.42)$ \\
\hline Hemoglobin $\left(\mathrm{g} x ~ d L^{-1}\right)$ & $13.3 \pm 0.7(11.5-14.7)$ & $15.1 \pm 0.9(13.2-16.1)$ \\
\hline Leucocytes $\left(\mu \mathrm{L}^{-1}\right)$ & $5180 \pm 644(4290-5830)$ & $7813 \pm 1701(5850-8830)^{*}$ \\
\hline Thrombocytes $\left(10^{3} \times \mu \mathrm{L}^{-1}\right)$ & $235 \pm 28(208-264)$ & $279 \pm 70(199-328)$ \\
\hline Quick value (\%) & $103 \pm 18(79-120)$ & $110 \pm 3(108-113)$ \\
\hline PTT (sec) & $29 \pm 2(27-32)$ & $26 \pm 2(24-27)$ \\
\hline Bilirubin ( $\mathrm{mg} \mathrm{x} \mathrm{L}^{-1}$ ) & $12.5 \pm 6.4(8.0-17)$ & $5.7 \pm 4.6(3.0-11.0)$ \\
\hline Cholesterol $\left(\mathrm{g} \mathrm{x} \mathrm{L}^{-1}\right)$ & $1.90 \pm 0.30(1.57-2.15)$ & $1.15 \pm 0.12(1.03-1.26)^{*}$ \\
\hline Triglycerides $\left(\mathrm{g} \times ~ L^{-1}\right)$ & $1.12 \pm 0.30(0.79-1.36)$ & $0.90 \pm 0.67(0.43-1.67)$ \\
\hline AST/GOT (U/L) & $27 \pm 4(24-32)$ & $28 \pm 6(22-32)$ \\
\hline ALT/GPT (U/L) & $21 \pm 8(12-30)$ & $29 \pm 4(25-32)$ \\
\hline LDH (U/L) & $152 \pm 18(132-166)$ & $153 \pm 43(107-193)$ \\
\hline $\mathrm{AP}(\mathrm{U} / \mathrm{L})$ & $54 \pm 20(38-83)$ & $80 \pm 9(70-86)$ \\
\hline GGT (U/L) & $10 \pm 6(5-18)$ & $22 \pm 7(16-29)$ \\
\hline Creatinine ( $\mathrm{mg} \mathrm{x} \mathrm{L}^{-1}$ ) & $9.5 \pm 1.3(8.0-11.0)$ & $10.3 \pm 2.3(9.0-13.0)$ \\
\hline Urea (mg x L-1) & $278 \pm 74(200-350)$ & $473 \pm 141(340-620)$ \\
\hline Uric acid (mg x L-1) & $56 \pm 20(41-84)$ & $81 \pm 36(53-121)$ \\
\hline
\end{tabular}

Fig. 4. Deuterium enrichment of choline, betaine and SAM during and after infusion of $\left[\mathrm{D}_{9}\right.$-methyl $]$ choline chloride. $\left[\mathrm{D}_{9}\right.$-methyl]choline chloride $(250 \mathrm{mg} / 70$ $\mathrm{kg}$ body weight) was administered over a $3 \mathrm{~h}$ period to fasting individuals. Plasma samples were drawn at $\mathrm{t}=1 \mathrm{~h}, 2 \mathrm{~h}, 3 \mathrm{~h}, 6 \mathrm{~h}, 9 \mathrm{~h}, 24 \mathrm{~h}, 33 \mathrm{~h}, 48 \mathrm{~h}$ and $72 \mathrm{~h}$ and analyzed by electrospray tandem mass spectrometry. Endogenous and $\mathrm{D}_{9}$-labeled choline and betaine were determined in plasma, and $\mathrm{D}_{9}$-enrichment of choline (A) and Betaine (B) are indicated as the ratio of the respective $\mathrm{D}_{9}$ label compared to endogenous metabolite. $\mathrm{D}_{3}$-enrichment of SAM over time (C) was calculated from the $\mathrm{D}_{6}-/\left(\mathrm{D}_{3}+\mathrm{D}_{6}\right)$ ratio of the respective metabolites as described elsewhere [21]. Data are means \pm SD of 4 controls (open symbols) and $3 \mathrm{CF}$ patients (filled symbols).

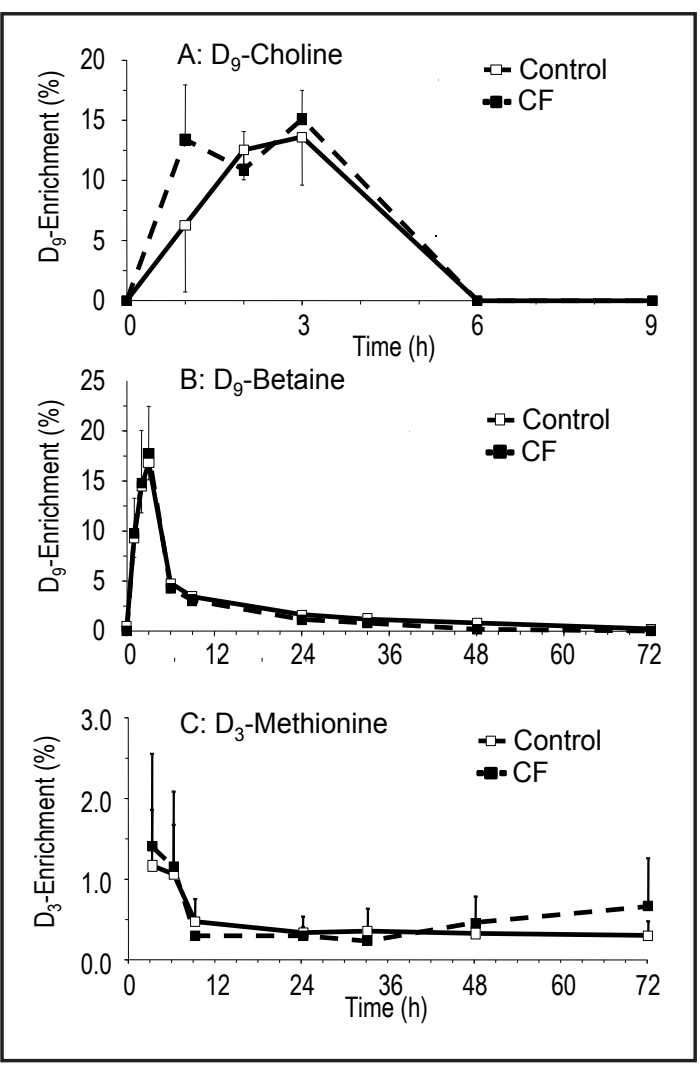

during infusion. [ $\mathrm{D}_{9}$-methyl]-enrichment of plasma choline during infusion (1$3 \mathrm{~h}$ ) was $13.4 \pm 1.1 \%$ and $13.1 \pm 1.2 \%$ for controls and CF patients, respectively ( $p$ 0.05), indicating no difference in deuterium enrichment in plasma. $\left[\mathrm{D}_{9}\right.$-methyl]-choline was completely removed from the circulation within $3 \mathrm{~h}$ from the end of infusion. Similarly, there was no significant difference in the enrichment of $\left[\mathrm{D}_{9}\right.$-methyl]-betaine (Fig. $4 \mathrm{~B}$ ), derived from $\left[\mathrm{D}_{9}\right.$-methyl]-choline oxidation, between $\mathrm{CF}$ and controls. In contrast to the label 
Fig. 5. Molecular composition of choline containing phospholipids (A) and of phosphatidyle thanolamine (B) in plasma of $\mathrm{CF}$ patients and control subjects undergoing. Data are indicated as means $\pm \mathrm{SD}$ of $\mathrm{CF}$ patients (black bars) compared to controls (white bars). Abbreviations: individual species of phosphatidylcholine (PC) and phosphatidyl-

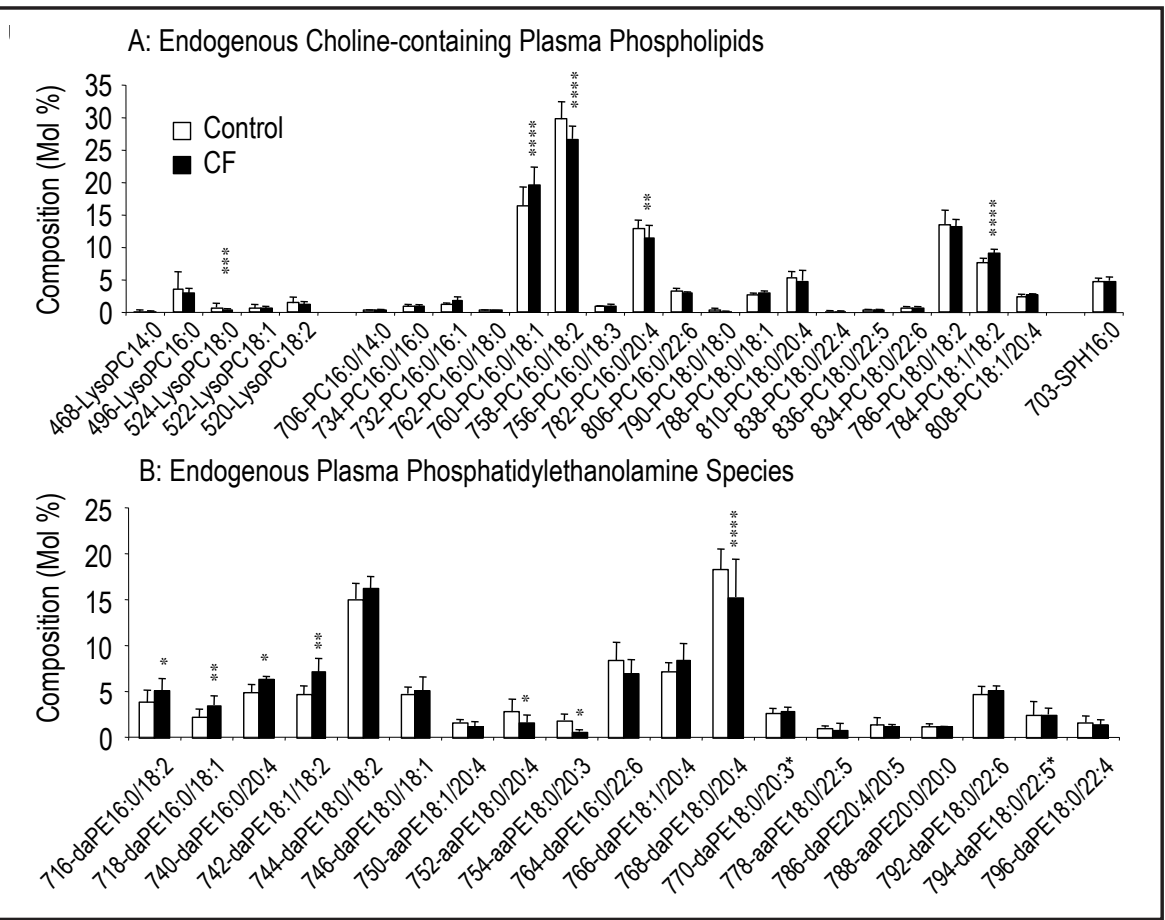
ethanolamine (PE) are defined by their two fatty acid codes separated by a slash. To identify a fatty acid residue, the number before the colon defines the number of carbon atoms, and the number after the colon the number of double bonds. This analogously holds for sphingomyelin (SPH) and Lyso-PC components comprizing only one fatty acid residue. The number in front of each component defines the mass by charge ratio of each component in positive ionization; ${ }^{*}, \mathrm{p}<0.05 ;{ }^{* *}, \mathrm{p}<0.01 ; * * * *, \mathrm{p}<0.0001$.

incorporation characteristics for choline, $\left[\mathrm{D}_{9}\right.$-methyl]-enrichment in betaine produced no plateau, and maximum enrichment in $\mathrm{CF}$ and controls was achieved at the end of infusion (3h) $\left(17.8 \pm 2.7\right.$ and $20.3 \pm 3.5 \%$, respectively $(p<0.05)$. $\mathrm{D}_{9}$-methyl]-betaine persisted for longer in the circulation in both CF patients and controls, and enrichment after 24 hours after onset of the infusion was $1.16 \pm 0.17 \%$ and $1.32 \pm 0.47 \%$, respectively $(p>0.05)$. Endogenous phosphocholine was at the limit of detection, and its deuterated derivative ([ $\mathrm{D}_{9}$-methyl]phosphocholine) below detection limit in both groups (data not shown). The $\mathrm{D}_{3}$-enrichment of methionine as calculated from $\mathrm{D}_{3}$ - and $\mathrm{D}_{6}$-labeled PC [21] was detectable from the end of $\left[\mathrm{D}_{9}\right.$-methyl]choline infusion ( $3 \mathrm{~h}$ ), and showed no significant difference between $\mathrm{CF}$ patients and controls (Fig. 4C). Mean values of enrichment were $1.30 \pm 0.30 \%$ and $1.15 \pm 0.37 \%$ at $3-6 \mathrm{~h}$, respectively $(p>0.05)$, and then decreased to $0.40 \pm 0.05 \%$ and $0.43 \pm 0.08 \%$ from $9-72 \mathrm{~h}$, respectively $(p>0.05)$.

Mass spectrometric analysis of endogenous choline-containing phospholipids and phosphatidylethanolamine

Tandem mass spectrometry (MS/MS) of plasma PC showed higher resolution and detection of individual molecular species (Fig. 5A) than HPLC (Fig. 1). The fraction of PC16:0/18:1 (mass by charge $[\mathrm{m} / \mathrm{z}]=+760)$ was higher than in controls $(\mathrm{p}<0.0001)$, whereas PC16:0/18:2 (m/z=+758) and PC16:0/20:4 (m/z=+782) were decreased $(\mathrm{p}<0.0001$ and $\mathrm{p}<0.01$, respectively) in these patients (Fig. 5A). Whereas PC18:1/20:4 (m/ $\mathrm{z}=784$ ) was increased $(\mathrm{p}<0.0001)$, there were no significant differences in other LC-PUFA-PC components. We summarized alterations in PC composition in the form of sub-groups (Table 2A), showing that, in spite of apparent significances, differences in PC composition between these CF and control persons were small.

Similarly, differences in endogenous PE composition were significant but small, with increased mono-, di- and poly-unsaturated PE species from the palmitoyl series, but 
Table 2. Choline-containing phospholipid and $\mathrm{PE}$ sub-groups of $\mathrm{CF}$ patients receiving $\left[\left[\mathrm{D}_{9}\right.\right.$-methyl $]$ choline $]$. $\mathrm{PC}$, Lyso-PC, sphingomyelin and PE were analysed as indicated in Materials and Methods. Data are indicated as means \pm SD. Abbreviations: PC, PE, C18:1, C18:2, C20:4, C22:6, LC-PUFA; *, p<0.05; **, $\mathrm{p}<0.01$; ***, $\mathrm{p}<0.001 ; * * * *, \mathrm{p}<0.0001$; n.s., not significant

\begin{tabular}{|c|c|c|}
\hline & Controls & CF patients \\
\hline \multicolumn{3}{|c|}{ A: Choline containing phospholipid sub-groups } \\
\hline C18:1-PC (Mol-\%) & $20.46 \pm 3.2$ & $24.43 \pm 3.51 * * * *$ \\
\hline C18:2-PC (Mol-\%) & $51.06 \pm 4.72$ & $49.16 \pm 3.04$ n.s. \\
\hline C20:4-PC (Mol-\%) & $20.98 \pm 2.15$ & $18.99 \pm 3.74 * *$ \\
\hline C22:6-PC (Mol-\%) & $4.10 \pm 0.51$ & $3.69 \pm 0.41 * * *$ \\
\hline LC-PUFA-PC (Mol-\%) & $25.09 \pm 2.48$ & $22.68 \pm 3.60 * *$ \\
\hline $\mathrm{C} 22: 6$ to $\mathrm{C} 20: 4$ ratio & $0.196 \pm 0.021$ & $0.202 \pm 0.047$ n.s. \\
\hline Lyso-PC (Mol-\%) & $6.68 \pm 5.06$ & $5.63 \pm 1.52$ n.s. \\
\hline Sphingomyelin (Mol-\%) & $4.75 \pm 0.58$ & $4.88 \pm 0.61$ n.s. \\
\hline \multicolumn{3}{|l|}{ B: PE sub-groups } \\
\hline C18:1-PE (Mol-\%) & $7.90 \pm 0.80$ & $9.53 \pm 2.45$ n.s. \\
\hline C18:2-PE (Mol-\%) & $24.99 \pm 3.64$ & $29.30 \pm 3.65$ n.s. \\
\hline C20:4-PE (Mol-\%) & $35.03 \pm 1.47$ & $32.82 \pm 4.39$ n.s. \\
\hline C22:6-PE (Mol-\%) & $15.09 \pm 2.88$ & $13.46 \pm 0.47$ n.s. \\
\hline LC-PUFA-PE (Mol-\%) & $53.13 \pm 2.09$ & $49.27 \pm 3.80$ n.s. \\
\hline $\mathrm{C} 22: 6$ to $\mathrm{C} 20: 4$ ratio & $0.525 \pm 0.239$ & $0.438 \pm 0.070$ n.s. \\
\hline Alkenyl-acyl-PE (Mol-\%) & $14.92 \pm 1.79$ & $9.85 \pm 3.25$ n.s. \\
\hline
\end{tabular}

Fig. 6. Plasma kinetics of phosphatidylcholine molecular species synthesized de novo and via PEMT pathway. Data are presented as $\%$ of total label of the major individual plasma PC species palmitoyl-oleoyl-PC (PC16:0/18:1, A), palmitoyllinoleoyl-PC (PC16:0/18:2, B), palmitoyl-arachidonoylPC (PC16:0/20:4, C), palmitoyl-d o c osa hexaen oyl-P C (PC16:0/22:6, D), stearoyl-arachidonoyl-PC (PC18:0/20:4, E) and stearoyl-docosahexaenoylPC (PC18:0/22:6, F), relative to total PC synthesized by the respective pathway. Data are means \pm SD of 4 controls (filled bars) and $3 \mathrm{CF}$ patients (open bars).

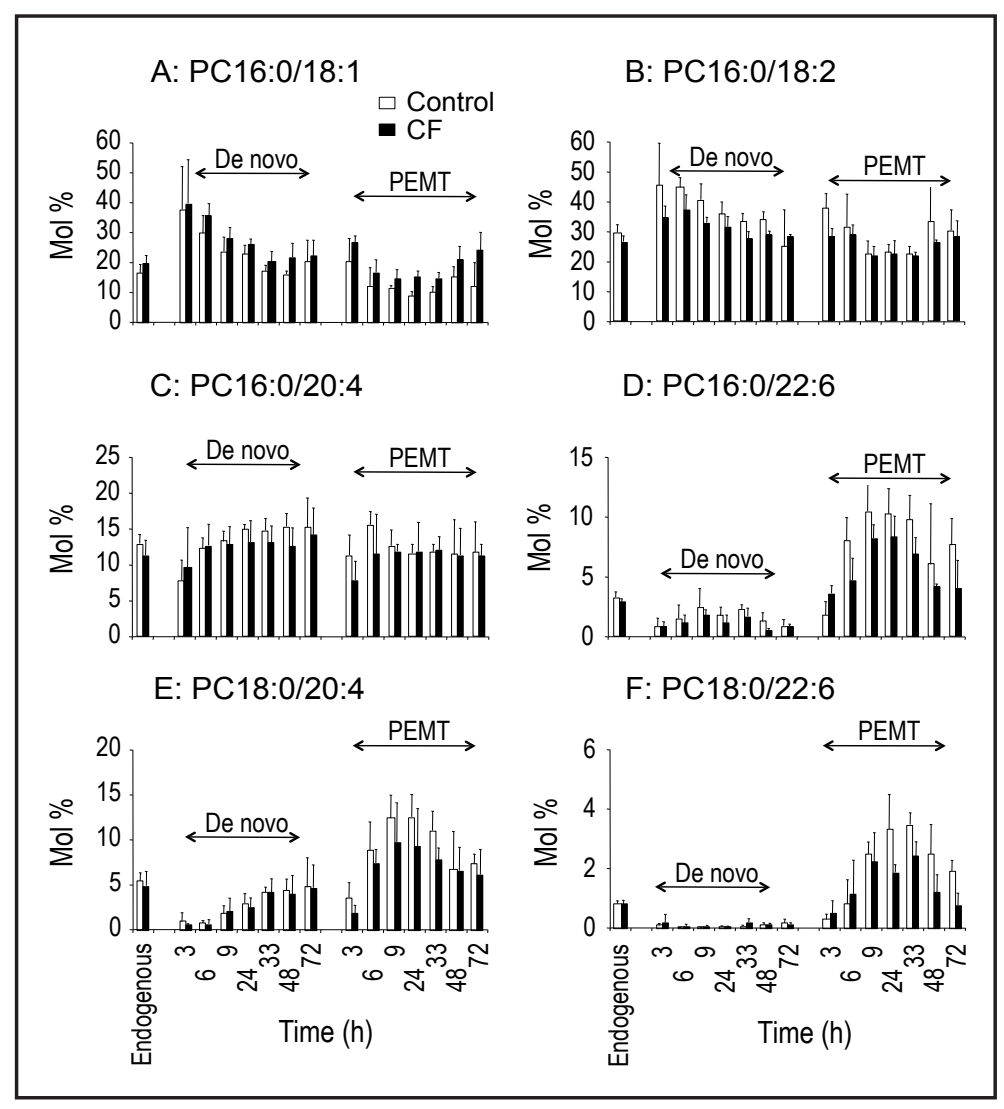

decreased components from the stearoyl serien (Fig. 5B). Taken together, C18:1- and C18:2PC were increased, whereas C20:4-PE was decreased. Alkenyl-PE species were decreased in CF. However, in spite of the decrease in LC-PUFA components, there was no difference in the C22:6 to C20:4-ratio of PC and PE (Table 2A, B). 
Fig. 7. Deuterium enrichment and concentrations of deuterated total plasma phosphatidylcholine following [ $\mathrm{D}_{9}$-methyl] choline chloride infusion. A and $\mathrm{C}$ show the direct incorporation of [ $\mathrm{D}_{9}$-methyl]-choline into plasma phosphatidylcholine (PC) via the Kennedy pathway resulting in $\mathrm{D}_{9}$-PC. $\mathrm{B}$ and D report values according to $\mathrm{PC}$ synthesis via sequential $D_{3}$-methylation of PE by the PEMT pathway resulting in $\mathrm{D}_{3 / 6}$-PC. Here $\left[\mathrm{D}_{9}\right.$-methyl]-choline is oxidized to $\left[\mathrm{D}_{9}\right.$-methyl $]$ betaine, and a $\mathrm{D}_{3}$-methyl group from [ $\mathrm{D}_{9}$-methyl]-betaine transferred to homocysteine to form $\mathrm{D}_{3}$-methionine via betaine homocysteine methyltransferase (EC: 2.1.1.5) (see Introduction). Enrichment is determined as the ratio between $\mathrm{D}_{9}-$ or $\mathrm{D}_{3+6}{ }^{-}$ label of PC components relative to total (deuterated and unlabeled) PC. Data are means \pm SD of 4 controls (open squares, continuous lines) and 3 CF patients (filled squares, dashed lines). Abbreviations: ${ }^{* * *}, \mathrm{p}<0.001$.

Synthesis and plasma kinetics of individual PC species synthesized de novo or via $N$-methylation of plasma $P C$

We assessed the contribution of PC synthesis de novo and via PE methylation by the PEMT pathway to the synthesis and kinetics of individual PC molecular species in CF compared to control subjects (Fig. 6). Both pathways significantly contributed to the synthesis of PC16:0/18:1, PC16:0/18:2 and PC16:0/20:4 (Fig. 6A-C). By contrast, PC16:0/22:6, PC18:0/20:4 and PC18:0/22:6 were nearly exclusively synthesized by the PEMT pathway (Fig. 6D-F), i. e. from their analogous PE precursors (Fig. 5B). The individual components showed different kinetics. For example, PC16:0/18:1 and PC16:0/18:2 derived from synthesis de novo decreased from 3-72h (Fig 6A, B), whereas stearoyl-arachidonoylPC (PC18:0/20:4) increased from 3h onwards (Fig 6E). The components preferentially synthesized by PEMT, i. e. PC16:0/20:4, PC16:0/22:6 and PC18:0/22:6 rapidly increased but after $24 \mathrm{~h}$ decreased again (Fig 6D-F). These metabolic principles held true for both CF patients and controls.

Precursor enrichment and concentrations of $D_{9}$ - and $D_{3 / 6}$-labeled plasma PC

$\left[\mathrm{D}_{\mathrm{q}}\right.$-methyl]choline enrichment of PC approached a maximum of $0.535 \pm 0.061$ and $0.561 \pm 0.038 \%$ at $33 \mathrm{~h}$ in controls and CF, respectively ( $p>0.05$ ) (Fig. $7 \mathrm{~A}) . \mathrm{D}_{3} / \mathrm{D}_{6}$-enrichment of plasma PC representing the PEMT pathway (Fig. 7B) peaked at $0.226 \pm 0.016 \%$ in controls (which is $29.7 \pm 2.1 \%$ of total enrichment) $33 \mathrm{~h}$ following the onset of the infusion. In CF patients, however, values were lower, with a maximum of $0.174 \pm 0.011(p<0.01)$, which is only $23.7 \pm 1.5 \%$ of total enrichment. From these enrichments and total (endogenous and deuterated) PC concentrations, we calculated the concentrations of $\mathrm{D}_{9}$ - and $\mathrm{D}_{3} / \mathrm{D}_{6}$-labeled PC in plasma of CF patients vs. controls. Concentration of $\mathrm{D}_{9}$-labeled $\mathrm{PC}$ linearly increased from 3 to $9 \mathrm{~h}$ after start of infusion, with increments of $0.880 \mu \mathrm{mol} / \mathrm{L}^{*} \mathrm{~h}^{-1}\left(\mathrm{R}^{2}=0.998\right)$ and $0.535 \mu \mathrm{mol} /$ 
Fig. 8. Kinetics of newly synthesized PC subgroups in plasma after $\left[\mathrm{D}_{9}\right.$-methyl]-choline infusion. PC species were sub-grouped according to their content of an oleic (C18:1) (A,E), linoleic $(\mathrm{C} 18: 2)(\mathrm{B}, \mathrm{F})$, arachidonic (C20:4) (C,G) or docosahexaenoic $(C 22: 6)$ acid $(D, H)$ residue as described before [27]. A-D indicate components synthesized de novo (Kennedy pathway; $\mathrm{D}_{9}-\mathrm{PC}$ ), whereas E-H indicate components synthesized via PE-methylation (PEMT-pathway; $\mathrm{D}_{3 / 6}$ PC). Data were calculated from the respective $\mathrm{D}_{9}$ or $\mathrm{D}_{3 / 6}$ enrichments, and total (deuterated and unlabeled) PC concentrations in plasma. Data are means \pm SD of 4 controls (open squares, continuous lines) and $\mathrm{N}=3 \mathrm{CF}$ patients (filled squares, dashed lines). Abbreviations: **, $\mathrm{p}<0.01$; ***, $\mathrm{p}<0.001$ vs control.

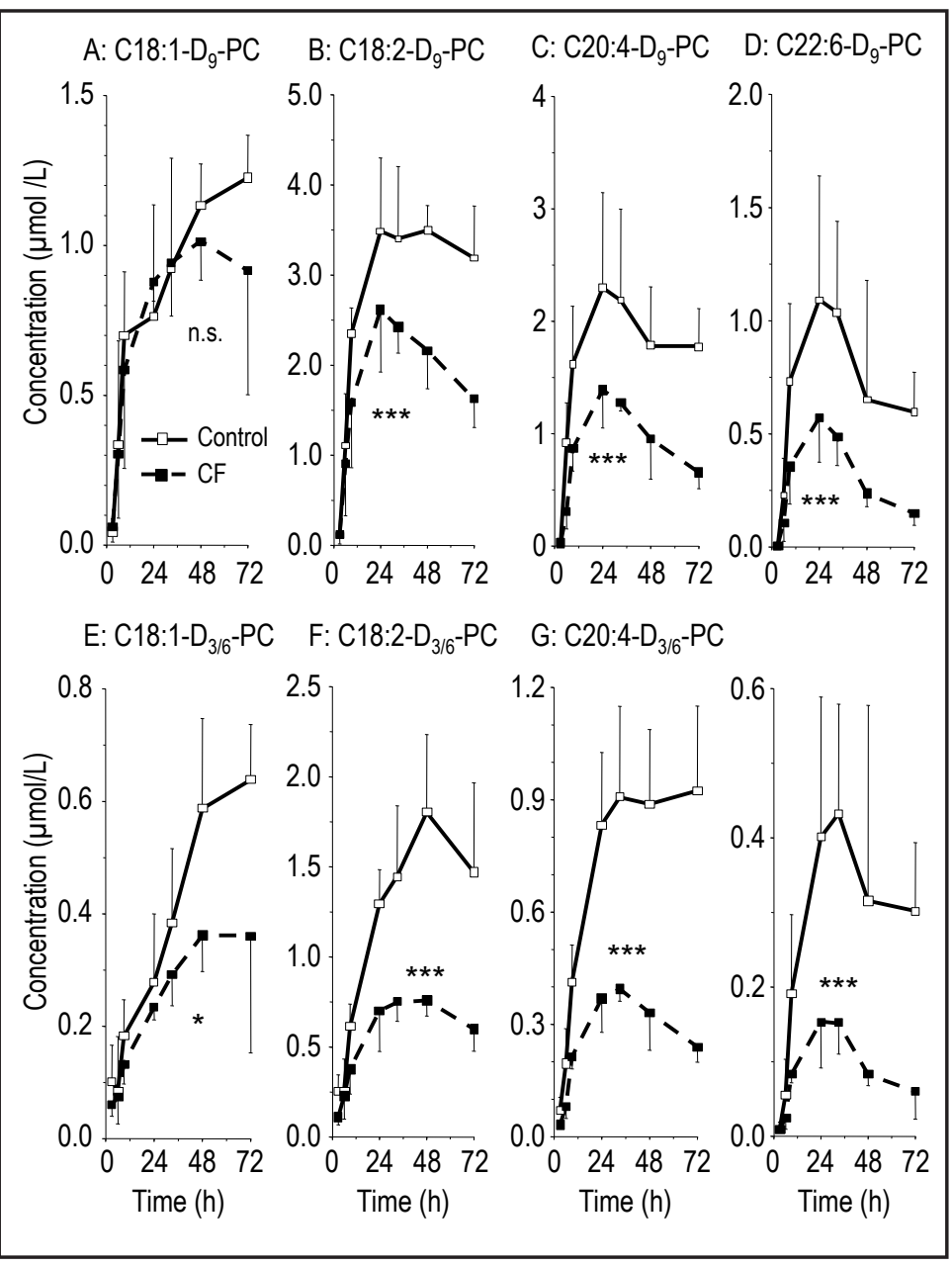

$\mathrm{L}^{*} \mathrm{~h}^{-1}\left(\mathrm{R}^{2}=0.996\right)$ for controls and CF patients, respectively. The curve than flattened, and concentration differences were significant from $24 \mathrm{~h}$ after start of infusion onwards, with a concentration of $\mathrm{D}_{9}$-labeled PC in CF comprising $62.4 \pm 4.3 \%$ of controls $(\mathrm{p}<0.001)$ (Fig. 7C). The increment in $\mathrm{D}_{3 / 6}$-labeled PC from 3 to $9 \mathrm{~h}$ was $0.162 \mu \mathrm{mol} / \mathrm{L}^{*} \mathrm{~h}^{-1}\left(\mathrm{R}^{2}=0.873\right)$ and $0.101 \mu \mathrm{mol} / \mathrm{L}^{*} \mathrm{~h}^{-1}\left(\mathrm{R}^{2}=0.963\right)$ for controls and CF patients respectively. Concentrations in $\mathrm{CF}$ between 24 and $72 \mathrm{~h}$ were significantly lower than in controls (Fig. 7D), comprising $46.9 \pm 2.6 \%$ of controls, which was a stronger decrease than that of $\mathrm{D}_{9}-\mathrm{PC}(p<0.01)$.

\section{Plasma kinetics of PC subgroups}

We then determined the concentrations of $\mathrm{D}_{9}$ - (Fig. 8A-D) and $\mathrm{D}_{3 / 6}$-labeled (Fig. 8E, H) PC sub-groups, namely C18:1-PC, C18:2-PC, C20:4-PC and C22:6-PC. Plasma concentrations of newly synthesized PC sub-groups were lower throughout irrespective of the underlying pathway, synthesis de novo or PE methylation via PEMT (Fig. 8), with the only exception of C18:1-PC, derived from de novo synthesis (C18:1-D - PC, Fig. 8A). However, decreases appeared larger for PCs derived from PEMT (Fig. 8E-H) than from direct incorporation of $\mathrm{D}_{9}$-choline (Fig. 8A-D).

\section{Discussion}

Disturbed choline and LC-PUFA homeostasis is critical to CF patients. However, data on clinical improvements by docosahexaenoic acid (C22:6) are conflicting [22, 28-30]. 


\section{Cellular Physiology Cell Physiol Biochem 2015;35:1437-1453 \begin{tabular}{l|l} 
and Biochemistry Published online: March 12, 2015 & $\begin{array}{l}\text { C 2015 S. Karger AG, Basel } \\
\text { www.karger.com/cpb }\end{array}$ \\
\hline
\end{tabular} \\ Grothe et al.: Clinical Impact of Phospholipid Alterations in CF}

LC-PUFA metabolism is intimately linked to that of choline, since PC is a major LC-PUFA carrier between the liver and other organs. Moreover, plasma PC is an important marker of an organism's LC-PUFA status, whereas cholesterol esters and triglycerides are of minor importance here $[21,27,31,32]$. Consequently, choline and PC homeostasis not only impact on liver metabolism, but also affect extrahepatic, clinically important parameters in CF: the lungs are compromised by chronic inflammation, even in the absence of bacterial or viral infection [33]. The release of IL-6 induces the formation of acute phase proteins by the liver, and is involved in the cross-talk between organs during inflammatory processes including lungs and liver [34-36]. The C20:4 and C22:6 moieties of plasma PC are important precursors of prostaglandins, leucotrienes and resolvins, being involved in inflammation and organ integrity [37]. Choline, an essential nutrient to all cells for membrane PC formation, particularly during cell proliferation and epithelial repair, and for the synthesis of VLDL-PC in liver, is deficient in CF patients $[13,18]$. Consequently, clinically important characteristics in CF disease, like impaired lung function and chronic inflammation, may be linked to impaired homeostasis, hepatic metabolism and peripheral supply of choline, total PC and LC-PUFA-PC. Interestingly, pro-apoptotic ceramides are increased in CF lungs [38, 39]. Here, choline in the form of PC is an essential co-substrate of sphingomyelin synthase (EC 2.7.8.27) for ceramide clearance [40]. Given that decreased plasma choline and PC in CF patients reflect their deficiency in peripheral organs, choline deficiency may contribute to increased pulmonary ceramide levels.

Plasma choline and PC concentration were lower in adult CF patients than in healthy individuals, which is consistent with impaired choline status, due to increased fecal losses of biliary PC $[8,13,27,41]$. The correlation between body mass index (BMI) and lung function $\left(\mathrm{FEV}_{1}\right)$ suggests that nutrients and gastrointestinal function are important to the clinical course of these patients [2,3]. In this context C20:4 and C22:6 status and supplementation have been investigated extensively in CF. Whereas C22:6 supplementation in neutral lipid form did not convincingly improve clinical outcome [29,30], there is so far no focus on choline deficiency, impaired PC homeostasis, and their link to C20:4 and C22:6 metabolism, in relation to clinical parameters. The data of this study, however, indicate that in $\mathrm{CF}$ decreased plasma choline and total PC, and their link to LC-PUFA via C20:4-PC and C22:6-PC metabolism, specifically relates to lung function impairment and inflammation.

In contrast to decreased C18:2-containing PC, we did not find a significant alteration in the mean molar fractions of $\mathrm{C} 20: 4-\mathrm{PC}$ or $\mathrm{C} 22: 6-\mathrm{PC}$, or in the ratio between $\mathrm{C} 20: 4-\mathrm{PC}$ and C22:6-PC. Generally, C20:4 and C22:6 alterations in CF are highly variable, depending on age and model, and are explained by altered fat supply and absorption. Hepatic triglyceride accumulation with an altered fatty acid composition is believed to contribute as well $[8,17,28,42]$. However, C20:4 and C22:6 supply is not impaired in CF patients [28, 42]. Triglycerides showed no differences in fatty acid composition and concentrations between CF patients and controls, with palmitic acid (C16:0) and C18:1 as major, and C20:4 and C22:6 as minor components (data not shown). Hence, the absolute decrease and high variability of LC-PUFA-PC in this study appears to relate to choline and PC metabolism rather than C20:4 and C22:6 availability. Consequently, the correlation between C20:4-PC and C22:6PC values and clinical parameters suggest that impaired choline and PC homeostasis rather than LC-PUFA deficiency is relevant. In this context, it is noteworthy that correlations to FEV1 and IL-6 occur in a parallel fashion for both C20:4-PC and C22:6-PC. This is in clear contradiction to the hypothesis of increased C20:4 at the expense of C22:6 as the cause for clinical impairment [28]. In contrast, our data support the superior relevance of choline deficiency, impairing total and LC-PUFA-PC metabolism and clinical parameters.

The superior relevance of choline and PC homeostasis to extra-hepatic organ function is supported by data showing that in deficient mice choline and PC are redistributed from peripheral organs to the liver [43]. Our results are in line with this: the direct correlation of choline, total PC, C20:4-PC and C22:6-PC with lung function - and inversely with inflammation - suggests a general role of choline and PC status for the patients' clinical course. Importantly, patients were separable into two groups: four patients had higher choline, PC, C20:4-PC 


\section{Cellular Physiology Cell Physiol Biochem 2015;35:1437-1453

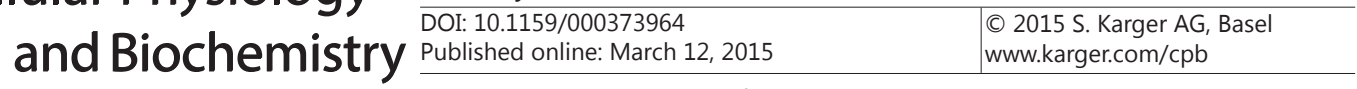 \\ Grothe et al.: Clinical Impact of Phospholipid Alterations in CF}

and C22:6-PC values and good lung function, whereas four other patients showed poor lung function, associated with lower levels of biochemical parameters. This discrimination of groups was most obvious for C22:6-PC (see Fig. 3B), the PC sub-group synthesized by the PEMT pathway, as demonstrated by $\left[\mathrm{D}_{9}\right.$-methyl]choline labeling (Fig. $6 \mathrm{D}+\mathrm{F}$ ). As this pathway is the only source of (limited) endogenous choline synthesis [11], severity of choline deficiency in CF patients may depend on PEMT activity, which is highly variable among individuals $[44,45]$. This consequently means that the necessity and magnitude of any putative choline substitution of CF patients is variable. Moreover, it means that plasma choline and PC may be useful screening parameters related to clinical outcome in CF.

\section{PC metabolism in CF plasma}

To address characteristic differences of choline and PC metabolism and plasma kinetics we employed, for the first time in CF patients, in vivo labeling with $\left[\mathrm{D}_{9}\right.$-methyl]choline $[21$, $26]$. This enabled us to investigate de novo synthesis of $P C$ via direct $\left[D_{9}\right.$-methyl]choline incorporation, the major source of mono- and di-unsaturated PC in plasma, resulting in the formation of $D_{9}$-labeled PC $[21,26]$. Additionally, $\left[D_{9}\right.$-methyl]choline labeling addresses PC synthesis from PE methylation by PEMT, which comprises about $30 \%$ of plasma PC and is the primary source of poly-unsaturated C20:4-PC and C22:6-PC: a fraction of administered [ $\mathrm{D}_{9}$ methyl $]$ choline is oxidized to $\left[\mathrm{D}_{9}\right.$-methyl] betaine, which then transfers a $\mathrm{D}_{3}$-methyl group to homocysteine via betaine homocysteine methyltransferase (EC: 2.1.1.5) to synthesize $\mathrm{D}_{3}$ methionine. This is subsequently activated to $D_{3}-S$-adenosylmethionine $\left(D_{3}-S A M\right) . D_{3}-S A M$ is then used for sequential PE-methylation by PEMT, resulting in $\mathrm{D}_{3} / \mathrm{D}_{6}$-rather than $\mathrm{D}_{9}$-labeled PC $[21,46,47]$.

After $\left[\mathrm{D}_{9}\right.$-methyl $]$ choline chloride infusion, $\left[\mathrm{D}_{9}\right.$-methyl $]$ choline enrichment of $\mathrm{PC}$ was identical in $\mathrm{CF}$ and control subjects. It is not possible to determine deuterium enrichment of intracellular precursors of PC synthesis for ethical reasons. As $\mathrm{D}_{9}$-enrichment in plasma choline was identical in CF and controls, and given that this is representative for the intracellular space, data indicate unchanged de novo PC synthesis in CF. However, this only means that synthesis is identical relative to the respective hepatic PC pools in the enrolled individuals. $\mathrm{D}_{3 / 6}$-enrichment of PC representing the PEMT pathway, however, was lower in $\mathrm{CF}$ compared to controls, although the estimated $\mathrm{D}_{3}$-enrichment of SAM was identical in both groups. In controls, it was about $30 \%$ of total deuterium-enrichment of plasma PC, which equals the estimated contribution of this pathway to normal hepatic PC metabolism [48], whereas it was less in CF patients. Hence, our data show that the PEMT pathway, was decreased in the enrolled 3 CF patients compared to controls. Inter-individual differences of PEMT activity, may explain for the differences in choline and PC homeostasis and clinical parameters across CF patients (see above).

Total concentrations of both newly synthesized $\mathrm{D}_{9}{ }^{-}$and $\mathrm{D}_{3 / 6}-\mathrm{PC}$ were lower in $\mathrm{CF}$ plasma. Substrate (choline, SAM) deficiency, the priority of biliary PC secretion over that of VLDL-PC [11], or their combination may contribute here. These data are consistent with the general impairments in choline and PC homeostasis we found in the whole study group, and may therefore be representative for CF patients. Importantly, choline substitution improves the methyl group status in CF patients [49]. However, effects on PC metabolism and PEMT activity were not investigated in that study. The hepatic status of the patients participating in $\left[\mathrm{D}_{9}\right.$-methyl]choline labeling was highly different, whereas metabolic alterations were similar. We therefore hypothesize that decreased hepatic PC secretion into plasma may be a general phenomenon in CF patients due to impaired choline status, which also explains for decreased plasma cholesterol [50]. Nevertheless, further mechanisms, like accelerated PC turnover in plasma due to peripheral consumption or hepatic uptake of high-density lipoproteins (HDL), being rich in cholesterol as well as in PC [19], may contribute. In essence, it will be important to assess in larger studies whether strategies to supplement choline and replenish the pool of one-carbon-units will normalize plasma choline and PC homeostasis, and will improve the clinical status in CF. Sub-grouping of PC [27] showed that only $\mathrm{D}_{9}$ C18:1-PC kinetics was unchanged. This is consistent with increased PC16:0/18:1 fractions 


\section{Cellular Physiology Cell Physiol Biochem 2015;35:1437-1453 \begin{tabular}{|c|c|c|}
\hline DOI: 10.1159/000373964 & O 2015 S. Karger AG, Basel \\
\hline
\end{tabular} www.karger.com/cpb

and unchanged concentrations in CF. Differences in other PC and PE molecular species of the individuals participating in the $\left[\mathrm{D}_{9}\right.$-methyl]choline labeling were of minor extent. The complex interactions of differential plasma turnover, trafficking of individual PC species to bile or VLDL, HDL uptake and the usage of LC-PUFA-PE components for the PEMT pathway $[11,21,51]$ lead to a complex situation, where stable isotope labeling and MS/MS analysis proved more sensitive than HPLC. However, all these aspects will have to be investigated in a larger number of CF patients in future.

\section{Conclusion and Clinical Perspective}

Our data point to a pathophysiological concept of impaired hepatic PC synthesis and secretion, based on choline deficiency. This contributes to the clinical status of CF patients, as plasma choline and PC concentrations directly correlate with lung function and inversely with inflammation. Hence, plasma choline and PC analysis may be clinically useful screening parameters. Inter-individual differences in PEMT activity, responsible for C22:6 and C20:4PC and (limited) endogenous choline synthesis, may contribute to the overall choline status of these patients. Research is needed to specify whether clinical status can be improved by choline substitution, which is momentarily addressed in a pilot study.

\section{Acknowledgements}

We thank the excellent technical assistance of Verena Müller, and the Medical Faculty of the Eberhard-Karls-University Tuebingen for grant support (AKF program). We thank Christian F. Poets, MD, for reviewing this manuscript.

This work was supported by an institutional grant of the Medical Faculty of the University of Tuebingen (E.0327017).

\section{References}

1 Bradbury NA: Intracellular CFTR: Localization and function. Physiol Rev 2011;79:S175-S191.

2 Cystic Fibrosis Foundation Patient Registry: Annual Data Report. Bethesda, Maryland, 2010, 32 p.; http:// www.cff.org/UploadedFiles/LivingWithCF/CareCenterNetwork/PatientRegistry/ 2010-Patient-RegistryReport.pdf.

3 Canadian Cystic Fibrosis Foundation Registry: Annual Report, Toronto, Ontario, 2011, 35 p.; http://www. cysticfibrosis.ca/wp-content/uploads/2013/10/Registry2011FINALOnlineEN.pdf.

4 Colombo C, Battezzati PM, Crosignani A, Morabito A, Costantini D, Padoan R, Giunta A: Liver disease in cystic fibrosis: a prospective study on incidence, risk factors, and outcome. Hepatology 2002;36:13741382.

5 Williams SM, Goodman R, Thomson R, Mchugh K, Lindsell DRM: Ultrasound evaluation of liver disease in cystic fibrosis as part of an annual assessment clinic: a 9-year review. Clin Radiol 2002;57:365-370.

6 Herrmann U, Dockter G, Lammert F: Cystic fibrosis-associated liver disease. Best Pract Res Clin Gastroenterol 2010;24:585-592.

7 Freudenberg F, Broderick AL, Yu BB, Leonard MR, Glickman JN, Carey MC: Pathophysiological basis of liver disease in cystic fibrosis employing a DeltaF508 mouse model. Am J Physiol Gastrointest Liver Physiol 2008;294:G1411-G1420.

8 Lindblad A, Glaumann H, Strandvik B: Natural history of liver disease in cystic fibrosis. Hepatology 1999;30:1151-1158.

9 Zeisel SH: Dietary choline: biochemistry, physiology, and pharmacology. Ann Rev Nutr 1981;1:95-121.

10 Walkey CJ1, Yu L, Agellon LB, Vance DE: Biochemical and evolutionary significance of phospholipid methylation. J Biol Chem 1998;273:27043-27046.

11 Li Z, Agellon LB, Vance DE: Phosphatidylcholine homeostasis and liver failure. J Biol Chem 2005;280:37798-37802. 


\section{Cellular Physiology Cell Physiol Biochem 2015;35:1437-1453 \begin{tabular}{l|l|l} 
DOI: 10.1159/000373964 & (C) 2015 S. Karger AG, Basel
\end{tabular} and Biochemistry Published online: March 12, $2015 \quad$ www.karger.com/cpb

12 Quinton PM: Cystic fibrosis: impaired bicarbonate secretion and mucoviscidosis. Lancet 2008;372:415417.

13 Chen AH, Innis SM, Davidson AG, James SJ: Phosphatidylcholine and lysophosphatidylcholine excretion is increased in children with cystic fibrosis and is associated with plasma homocysteine, S-adenosylhomocysteine, and S-adenosylmethionine. Am J Clin Nutr 2005;81:686-691.

14 Scheele GA, Fukuoka SI, Kern HF, Freedman SD: Pancreatic dysfunction in cystic fibrosis occurs as a result of impairments in luminal pH, apical trafficking of zymogen granule membranes, and solubilization of secretory enzymes. Pancreas 1996;12:1-9.

15 Nouri-Sorkhabi MH, Chapman BE, Kuchel PW, Gruca MA, Gaskin KJ: Parallel secretion of pancreatic phospholipase A2, phospholipase A1, lipase and colipase in children with exocrine pancreatic dysfunction. Pediatr Res 2000;48:735-740.

16 Koc H, Mar MH, Ranasinghe A, Swenberg JA, Zeisel SH: Quantitation of choline and its metabolites in tissues and foods by liquid chromatography/electrospray ionization-isotope dilution mass spectrometry. Anal Chem 2002;74:4734-4740.

17 Greenberger NJ, Isselbacher KJ: Diseases of the gallbladder and bile ducts; in: Fauci A, Braunwald E, Isselbacher KJ, Wilson JD, Martin JB (eds): Harrison's principles of internal medicine. New York, McGrawHill, 1998, pp 1725-1726.

18 DRI DIETARY REFERENCE INTAKES FOR Thiamin, Riboflavin, Niacin, Vitamin B6, Folate, Vitamin B12, Pantothenic Acid, Biotin, and Choline. A Report of the Standing Committee on the Scientific Evaluation of Dietary Reference Intakes and its Panel on Folate, Other B Vitamins, and Choline and Subcommittee on Upper Reference Levels of Nutrients, Food and Nutrition Board, Institute of Medicine, National Academy Press, Washington, D.C., 1998; http://www.nap.edu/catalog/6015.html.

19 The AOCS Lipid Library: Plasma lipoproteins - composition, structure and biochemistry, 2013; http:// lipidlibrary.aocs.org/lipids/lipoprot/index.htm.

20 Noga AA, Zhao Y, Vance DE: An unexpected requirement for phosphatidylethanolamine N-methyltransferase in the secretion of very low density lipoproteins. J Biol Chem 2002;277:42358-42365.

21 Pynn CJ, Henderson NG, Clark H, Koster G, Bernhard W, Postle AD: Specificity and rate of human and mouse liver and plasma phosphatidylcholine synthesis analyzed in vivo. J Lipid Res 2011;52:399-407.

22 Innis SM, Hasman D: Evidence of choline depletion and reduced betaine and dimethylglycine with increased homocysteine in plasma of children with cystic fibrosis. J Nutr 2006;136: 2226-2231.

23 Cole LK, Vance JE, Vance DE: Phosphatidylcholine biosynthesis and lipoprotein metabolism. Biochim Biophys Acta 2012;1821:754-761.

24 Bernhard W, Pynn CJ, Jaworski A, Rau GA, Hohlfeld JM, Freihorst J, Poets CF, Stoll D, Postle AD: Mass spectrometric analysis of surfactant metabolism in human volunteers using deuterated choline. Am. J. Respir. Crit. Care Med 2004;170:54-58.

25 Bligh EG, Dyer WJ: A rapid method of total lipid extraction and purification. Can J Biochem Physiol 1959;37:911-917.

26 Pynn CJ, Picardi MV, Nicholson T, Wistuba D, Poets CF, Schleicher E, Perez-Gil J, Bernhard W:. Myristate is selectively incorporated into surfactant and decreases dipalmitoylphosphatidylcholine without functional impairment. Am J Physiol Regul Integr Comp Physiol 2010;299:R1306-R1316.

27 Bernhard W, Raith M, Koch V, Kunze R, Maas C, Abele H, Poets CF, Franz AR: Plasma phospholipids indicate impaired fatty acid homeostasis in preterm infants. Eur J Nutr 2014;53:1533-1547

28 Freedman SD, Blanco PG, Zaman MM, Shea JC, Ollero M, Hopper IK, Weed DA, Gelrud A, Regan MM, Laposata M, Alvarez JG, O'Sullivan BP: Association of cystic fibrosis with abnormalities in fatty acid metabolism. N Engl J Med 2004;350:560-569.

29 Leggieri E, De Biase RV, Savi D, Zullo S, Halili I, Quattrucci S: Clinical effects of diet supplementation with DHA in pediatric patients suffering from cystic fibrosis. Minerva Pediatr 2013;65:389-398.

30 Alicandro G, Faelli N, Gagliardini R, Santini B, Magazzù G, Biffi A, Risé P, Galli C, Tirelli AS, Loi S, Valmarana L, Cirilli N, Palmas T, Vieni G, Bianchi ML, Agostoni C, Colombo C: A randomized placebo-controlled study on high-dose oral algal docosahexaenoic acid supplementation in children with cystic fibrosis. Prostaglandins Leukot Essent Fatty Acids 2013;88:163-169.

31 Browning LM, Walker CG, Mander AP, West AL, Madden J, Gambell JM, Young S, Wang L, Jebb SA, Calder PC: Incorporation of eicosapentaenoic and docosahexaenoic acids into lipid pools when given as supplements providing doses equivalent to typical intakes of oily fish. Am J Clin Nutr 2012;96:748-758. 


\section{Cellular Physiology Cell Physiol Biochem 2015;35:1437-1453 \begin{tabular}{l|l|l|}
\cline { 2 - 2 } DOI: 10.1159/000373964 & C 2015 S. Karger AG, Basel
\end{tabular} www.karger.com/cpb

32 Hoving EB, van Beusekom M, Nijeboer HJ, Muskiet FAJ: Gestational age dependency of essential fatty acids in cord plasma cholesterol esters and triglycerides. Ped Res 35:461-469.

33 Uhlig, S., Gulbins, E. (2008) Sphingolipids in the lungs.Am J Respir Crit Care Med 1994;178:1100-1114.

34 Rincon M, Irvin CG: Role of IL-6 in asthma and other inflammatory pulmonary diseases. Int J Biol Sci. 2012;8:1281-1290.

35 Rehermann B, Trautwein C, Böker KH, Manns MP (1992) Interleukin-6 in liver diseases. J Hepatol 2012;15:277-280.

36 El-Kadre LJ, Tinoco AC: Interleukin-6 and obesity: the crosstalk between intestine, pancreas and liver. Curr Opin Clin Nutr Metab Care 2013;16:564-568.

37 Ji RR, Xu ZZ, Strichartz G, Serhan CN: Emerging roles of resolvins in the resolution of inflammation and pain. Trends Neurosci 2011;34:599-609.

38 Hamai H, Keyserman F, Quittell LM, Worgall TS: Defective CFTR increases synthesis and mass of sphingolipids that modulate membrane composition and lipid signaling. J Lipid Res 2009;50:1101-1108.

39 Grassmé H, Riethmüller J, Gulbins E: Ceramide in cystic fibrosis. Handb Exp Pharmacol 2013;216:265-74.

40 Tafesse FG, Ternes P, Holthuis JCM: The multigenic sphingomyelin synthase family. J Biol Chem 2006;281:29421-29425.

41 Colombo C, Russo MC, Zazzeron L, Romano G: Liver Disease in Cystic Fibrosis. J Ped. Gastroent Nutr 2006;43:S49-S55.

42 Mimoun M, Coste TC, Lebacq J, Lebecque P, Wallemacq P, Leal T, Armand M: Increased tissue arachidonic acid and reduced linoleic acid in a mouse model of cystic fibrosis are reversed by supplemental glycerophospholipids enriched in docosahexaenoic acid. J Nutr 2009;139:2358-2364.

43 Li Z, Agellon LB, Vance DE: Choline redistribution during adaptation to choline deprivation. J Biol Chem 2007;282:10283-10289.

44 da Costa KA, Corbin KD, Niculescu MD, Galanko JA, Zeisel SH. Identification of new genetic polymorphisms that alter the dietary requirement for choline and vary in their distribution across ethnic and racial groups. FASEB J. 2014;28:2970-2978.

45 da Costa KA, Sanders LM, Fischer LM, Zeisel SH. Docosahexaenoic acid in plasma phosphatidylcholine may be a potential marker for in vivo phosphatidylethanolamine N-methyltransferase activity in humans. Am J Clin Nutr. 2011;93:968-974.

46 Singh PR, Lele SS, Mukherjee MS: Gene polymorphisms and low dietary intake of micronutrients in coronary artery disease. J Nutrigenet Nutrigenomics 2011;4: 203-209.

47 DeLong CJ, ShenY-J, Thomas MJ, Cui Z: Molecular distinction of phosphatidylcholine synthesis between the CDP-choline pathway and phosphatidylethanolamine methylation pathway. J Biol Chem 1999;274:2968329688.

48 Li Z, Vance DE: Phosphatidylcholine and choline homeostasis. J Lipid Res 2008;49: 1187-1194.

49 Innis SM, Davidson AG, Melynk S, James SJ: Choline-related supplements improve abnormal plasma methionine-homocysteine metabolites and glutathione status in children with cystic fibrosis. Am J Clin Nutr 2007;85:702-708.

50 Greenberg LD: Plasma cholesterol levels of monkeys maintained on various controlled and deficient diets. Am J Clin Nutr 1970;23:1101-1104.

51 Agellon LB, Walkey CJ, Vance DE, Kuipers F, Verkade HJ: The unique acyl chain specificity of biliary phosphatidylcholines in mice is independent of their biosynthetic origin in the liver. Hepatology 1999;30:725-729. 